\title{
Evaluation of the toxic effects of the aqueous extract of Niprineem tea in mice and rats
}

\author{
Obi Peter ADIGWE ${ }^{1}$, Lucy Binda JOHN-AFRICA ${ }^{2 *}$, Bulus ADZU ${ }^{2}$, \\ Gloria Ahunna AJOKU ${ }^{3}$, Abubakar Mustapha DANRAKA ${ }^{1}$ and Jemilat Aliyu IBRAHIM ${ }^{4}$ \\ ${ }^{1}$ Office of the Director General, Nigeria. \\ ${ }^{2}$ Department of Pharmacology and Toxicology, Nigeria. \\ ${ }^{3}$ Department of Medicinal Chemistry and Quality Control, Nigeria. \\ ${ }^{4}$ Department of Medicinal Plants Research and Traditional Medicine, National Institute for \\ Pharmaceutical Research and Development, Idu Industrial Area, PMB 21, Garki Abuja, Nigeria. \\ *Corresponding author; E-mail: lbjafrica@yahoo.com; Tel. +2348058577557
}

\begin{abstract}
\begin{tabular}{lll}
\hline Received: 28-04-2021 & Accepted: 20-10-2021 & Published: 30-10-2021 \\
\hline
\end{tabular}
\section{ABSTRACT}

Azadirachta indica is an important plant in traditional complementary and alternative medicine with decoctions (tea) being a common mode of administration. Herbal teas are frequently self-administered thus the need to prepare a standardized dosage form for the administration of such decoctions. The leaf of Azadirachta indica was formulated for administration as tea; thus, this study was designed to determine the safety profile of Niprineem tea. Oral acute and sub-chronic toxicity studies of the aqueous extract of Niprineem tea (NTE) were evaluated. The OECD (No 423) limit test was followed to determine the LD50 in Swiss albino mice, while OECD 407 guideline was used for the sub-chronic toxicity studies in Wistar rats. Acute administration of NTE did not cause detectable signs of toxicity in treated animals and no mortality was recorded. In the 28-day toxicity tests, there were no significant $(\mathrm{p}<0.05)$ changes in food and water intake, or urine and faecal output. Haematological analysis did not show deleterious effects in treated rats. Biochemical evaluation of indicators for renal and hepatic functions did not show significant changes after treatment with NTE. Likewise, histological tests did not result in structural changes in cells of the tissues of major organs. The results obtained suggest that Niprineem tea is relatively non-toxic and safe at the tested dose.
\end{abstract}

(C) 2021 International Formulae Group. All rights reserved.

Keywords: Azadirachta indica, neutraceutical, safety profile, decoction.

\section{INTRODUCTION}

Medicinal plants have formed the basis of healthcare throughout the world from the beginning of humanity and are still used widely (Ashafa et al., 2012). The use of nutraceuticals is on the rise because they are believed to be beneficial for the well-being of individuals. Herbal teas are a popular and convenient means for the administration of herbs with medicinal actions. Niprineem tea is a product developed by the National Institute for Pharmaceutical Research and Development for use as a nutraceutical because of the wide spectrum of medicinal characteristics attributed to the plant (Alzohairy, 2016). 
Azadirachta indica (A. Juss), (family, Meliaceae) is popularly known as Neem is also called 'dogon yaro' in Hausa, 'igi kasia' in Yoruba, and 'ogwu-akum' in Igbo in Nigeria (Ogbuewu et al., 2011; Fatoba et al., 2018). The plant is probably one of the most studied and widely used medicinal plants of all ages (Nwachukwu and Iweala, 2009). The specie is currently being cultivated globally because of its ability to adapt to different climatic conditions (Ashafa et al., 2012). Azadirachta indica $\mathrm{L}$. (neem) plays a therapeutic role in health management being a rich source of various types of chemical constituents which include azadirachtin nimbolinin, nimbin, nimbidin, nimbidol, sodium nimbinate, gedunin, salannin, and quercetin. The leaves contain ingredients such as nimbin, nimbanene, 6-desacetylnimbinene, nimbandiol, nimbolide, ascorbic acid, nhexacosanol, amino acid, 7-desacetyl-7benzoylazadiradione, 7-desacetyl-7benzoylgedunin, 17-hydroxyazadiradione, and nimbiol (Sadeghian and Mortazaienezhad 2007; Elteraifi and Hassanali, 2013; Hossain et al., 2013). Quercetin and $\beta$ sitosterol, polyphenolic flavonoids, were purified from fresh neem leaves and were known to have antibacterial and antifungal properties (Mahmoud et al., 2011).

The plant, $A$. indica has demonstrated a broad range of pharmacological activity which include antioxidant action, anti-inflammatory, neuroprotective, nephroprotective, hepatoprotective, antiviral, antibacterial, antifungal, antimalarial, anticancer, immunomodulatory, blood glucose-lowering and wound healing effects (Mahabub-UzZaman et al., 2009; Tiwari et al., 2014; Alzohairy, 2016). Neem extracts have also demonstrated insecticidal and potential antiandrogenic actions (Aladakatti et al., 2010; Mondédji et al., 2016). Several previous studies have been done on extracts of Azadirachta indica using both in-vivo and invitro models (Bakr, 2013; Islas et al., 2020; Jeba Malar et al., 2020). Niprineem tea is derived from the processed leaf of the plant, Azadirachta indica. Teas, infusions, and decoctions are simple modes of administration of plants with acclaimed medicinal value (Chandrasekara and Shahidi, 2018). However unregulated intake of herbal teas may result in the manifestation of toxic effects (Talib et al., 2020). This work was therefore designed to determine the acute and sub-chronic toxicological profile of Niprineem tea extract using mice and rats.

\section{MATERIALS AND METHODS}

This study was carried out in the laboratories of the National Institute for Pharmaceutical Research and Development, Idu Industrial Area, Abuja, Nigeria.

\section{Preparation of the aqueous extract of Niprineem tea (NTE)}

Leaves of Azadirachta indica were collected from NIPRD garden, located at Idu Industrial Area, Abuja. It was identified and authenticated at NIPRD herbarium where a voucher specimen was also deposited (No: NIPRD/H/17194). The leaves were dried to constant weight over a period of 3 days at 35 $40{ }^{\circ} \mathrm{C}$ in a thermostatic drying cabinet. The dried leaves were milled to a fine powder using an electric crusher machine. The tea was prepared following the manufacturer's recommendations. The tea bag (containing $4 \mathrm{~g}$ of tea product) was steeped in $250 \mathrm{ml}$ of boiling water and allowed to stand for 5 minutes after which the tea bag was removed and pressed out. This was carried out repeatedly. The water extracts were pooled and subsequently placed on a hot water bath, set at $55^{\circ} \mathrm{C}$ to evaporate to dryness to yield a dark green semi-solid extract (\% yield $23.93 \pm 1.76$ ).

\section{Animals}

Swiss albino mice $(26-33 \mathrm{~g})$ and Wistar rats $(120-220 \mathrm{~g})$ were obtained from the Animal Facility Centre of the National Institute for Pharmaceutical Research and Development, Idu Industrial Area, Abuja, Nigeria. The animals were housed under ambient conditions and fed on a standard rodent diet and clean drinking water ad libitum. Ethical approval for the study was obtained from the Institutional Animal Care and Ethics (ACE) Committee (NIPRD.05.03.05-09). 


\section{Oral acute toxicity test in mice}

The limit test of the OECD 2001 (No 423) was followed. Female mice were weighed and randomly placed in 3 groups of 3 mice each; a control group and two test groups.

The animals were treated as follows:

- Group 1: Distilled Water $10 \mathrm{ml} / \mathrm{kg}$;

- Group 2: NTE $2000 \mathrm{mg} / \mathrm{kg}$;

- Group 3: NTE $5000 \mathrm{mg} / \mathrm{kg}$.

The animals were observed for behavioural changes that include hyperactivity, aggression, passivity, stereotypy, and signs of toxicity such as changes in respiration, abdominal constriction, diarrhoea, sedation, tail erection, tremors, convulsion, coma and death. Animals were observed closely for the first 30 min after drug administration, and then periodically during the first $24 \mathrm{~h}$ with special attention given during the first 4 hours. For mice in group 3, one animal was dosed at a given time and treated at $24 \mathrm{~h}$ intervals. All animals were monitored for a period of 14 days and weighed on days 0,7 , and 14 . Testing the extract at the dose level of $5000 \mathrm{mg} / \mathrm{kg}$ was carried out as the plant is widely used as an herbal therapy for many disease conditions. The parameters used to monitor and record observations of the animals are from an adaptation of a table from the Malone and Robichaud Hippocratic Screening table (Malone and Robichaud, 1962). On day 14, the animals were euthanized by inhalation with diethyl ether. The internal organs were isolated and placed on filter paper to blot out excess blood. The organs were observed and weighed. The relative organ weight was then calculated using the formula:

$$
\begin{aligned}
& \begin{array}{l}
\text { Relative organ weight } \\
=\frac{\text { Weight of organ }(\mathrm{g})}{\text { weight of the animal on the day }} \\
\text { of sacrifice }(\mathrm{g})
\end{array}
\end{aligned}
$$

\section{Sub-chronic toxicity studies in rats}

Before commencement of treatment, rats were placed in the metabolic cages (Techniplast ${ }^{\circledR}$ metabolic cage systems for rats) for a five-day acclimatization period. The doses used for the toxicity test were derived from the equivalent human doses based on the method of Reagan-Shaw et al. (2007). Rats of both sexes were assigned into three groups; one control and two treatment groups. The extract was freshly prepared on each day and administered by gavage as a single daily dose while the control received water (the vehicle). Behavioural patterns of the animals were observed, feed consumption, water intake, faeces, and urine were assessed on daily and rats weighed once a week. At the end of the experiment, all animals were euthanized and blood samples were collected by cardiac puncture in a $5 \mathrm{ml}$ syringe using a $21 \mathrm{G}$ needle into non-heparinized and ETDA-containing tubes for biochemical and haematological analysis. After blood collection, all major internal organs such as liver, kidney, brain, lungs, spleen, stomach, small intestine, gonads were excised blotted of blood, weighed and observed macroscopically. The relative organ weights were calculated. The organs were preserved in $10 \%$ buffered formalin and subjected to pathological analysis (OECD, 2008). Haematology was carried out using an automated YNH7021 haematology analyzer while the biochemical analysis was done using Ranbaxy commercial kits following manufacturers' specification.

\section{Statistical analysis}

Results were expressed as mean \pm standard error of mean (SEM). Data were analyzed using analysis of variance (ANOVA). Results were regarded as significant at $\mathrm{P}<0.05$. The software package Graph pad PRISM 6 was used to analyze the data.

\section{RESULTS}

\section{Study on oral acute toxicity}

Administration of the extract of Niprineem tea did not cause behavioural change in the animals, no signs of toxicity were detected in all treated animal and no mortality was recorded during the 14-day observation period. There was also no significant $(\mathrm{p}<0.05)$ change in the body weight of the animals (Table 1) and the relative organ weights were also not significantly different from control (Table 2). On macroscopic examination of the organs such as lungs, liver and kidneys, no congestion, oedema or lesions were observed. 


\section{Sub-chronic toxicity test}

After oral administration of the tea extract to rats for 28 days at 250 and $500 \mathrm{mg} / \mathrm{kg}$ respectively, there was no death recorded in any of the animals during the study. No piloerection or diarrhea was observed. The behavioral pattern observed during the study was similar for animals in control and treated groups. There was gradual weight gain in all treated animals but the body weight was not statistically different from control group. The quantity of food consumed by the animals did not alter significantly between the control and treated groups during the test period. This trend was also observed for the faecal and urine output (Table 3).

\section{Effects of Niprineem Tea on haematological parameters}

Treatment of the rats with extract of Niprineem tea cause significant $(p<0.001)$ decrease in the platelet count (PLT). An increasing trend was observed in the values of some of haematological parameters evaluated, these include white blood cells, lymphocytes (LYM) and neutrophils (NEUT). The red blood cell count and the other red cell indices, haematocrit (HCT), haemoglobin (HGB), mean cell hemoglobin $(\mathrm{MCH})$, mean cell hemoglobin concentration (MCHC), mean corpuscular volume (MCV) also showed increasing trend. But despite the trend, the observed increase was however not significantly different when compared to control groups as shown in Table 4.

\section{Effects on biochemical parameters}

Treatment of rats with the tea extract did not cause significant changes in the serum level of glucose and total proteins. Renal parameters that include creatinine and urea were not significantly affected by treatment. The electrolyte levels were comparable to control groups and parameters of the lipid profile (Cholesterol, triglycerides, lipoproteins) were also not significantly different from control animals. Dose-dependent statistically significant $(\mathrm{p}<0.0001)$ increase in the value of the hepatic enzyme alkaline phosphatase (ALP) was observed in treated rats (Table 5).

\section{Effect on relative organ weight}

The relative organ weights of rat treated with Niprineem tea extract for 28 days is shown in Table 6. No significant difference was observed between the control and extract treated groups. Also on gross examination, oedema, lesions or signs of congestions were not observed.

\section{Histological examination}

Macroscopic examination of organs showed normal features and colour of the tissues, without apparent pathological changes in the major internal organs of treated animals. Microscopic examination of the tissues of these organs of the rats that were treated with Niprineem tea extract at 250 and $500 \mathrm{mg} / \mathrm{kg}$ showed normal cellular structures. There were no treatment-related changes on histological evaluation of the heart, liver, kidney, spleen, lung, stomach, cerebral cortex, testis, small intestine and uterine tissues (Table 7).

Table 1: Effect of Niprineem tea extract (NTE) on bodyweight of mice after acute oral administration.

\begin{tabular}{llccc}
\hline \multicolumn{1}{c}{ Treatment } & \multicolumn{1}{c}{ Dose $(\mathbf{m g} / \mathbf{k g})$} & \multicolumn{3}{c}{ Bodyweight $(\mathbf{K g})$} \\
\cline { 3 - 5 } Control & $10 \mathrm{ml} / \mathrm{kg}$ & $0.020 \pm 0.0003$ & $0.023 \pm 0.0003$ & $0.025 \pm 0.0006$ \\
NTE & 2000 & $0.021 \pm 0.0007$ & $0.024 \pm 0.0010$ & $0.025 \pm 0.0003$ \\
NTE & 5000 & $0.021 \pm 0.0005$ & $0.023 \pm 0.0003$ & $0.026 \pm 0.0003$ \\
\hline
\end{tabular}

Values Mean \pm SEM, $n=3$; Two-Way ANOVA, no significant difference between control and treated group $\mathrm{p}<0.05$. 
Table 2: Effect of Niprineem tea extract (NTE) on relative organ weight of mice after acute oral administration.

\begin{tabular}{cccc}
\hline Organ & Vehicle 10 ml/kg & NTE 2000 $\mathbf{~ m g} / \mathbf{k g}$ & NTE 5000 $\mathbf{~ g g / k g}$ \\
\hline Kidneys & $1.07 \pm 0.03$ & $1.05 \pm 0.05$ & $1.05 \pm 0.04$ \\
Liver & $5.72 \pm 0.25$ & $5.63 \pm 0.27$ & $5.65 \pm 0.10$ \\
Lungs & $1.17 \pm 0.17$ & $1.15 \pm 0.12$ & $1.06 \pm 0.09$ \\
Brain & $1.23 \pm 0.05$ & $1.17 \pm 0.09$ & $1.21 \pm 0.08$ \\
Heart & $0.63 \pm 0.02$ & $0.63 \pm 0.03$ & $0.62 \pm 0.04$ \\
Spleen & $1.04 \pm 0.04$ & $1.00 \pm 0.02$ & $1.01 \pm 0.01$ \\
Uterus & $0.79 \pm 0.07$ & $0.80 \pm 0.003$ & $0.78 \pm 0.03$ \\
\hline
\end{tabular}

$\mathrm{NTE}=$ Niprineem tea extract; Values Mean \pm SEM, $\mathrm{n}=3$; Two-Way ANOVA, no significant difference between control and treated group $\mathrm{p}<0.05$.

Table 3: Effect of Niprineem tea extract on body weight, food and water intake, faecal and urine output of rats.

\begin{tabular}{|c|c|c|c|c|c|}
\hline Parameter & $\mathbf{D}_{0}$ & $\mathbf{D}_{7}$ & $D_{14}$ & $\mathbf{D}_{21}$ & $\mathbf{D}_{28}$ \\
\hline \multicolumn{6}{|c|}{ Vehicle $10 \mathrm{ml} / \mathrm{kg}$} \\
\hline Body weight & $144.17 \pm 9.69$ & $152.83 \pm 12.02$ & $160.50 \pm 11.62$ & $166.83 \pm 14.25$ & $171.17 \pm 14.83$ \\
\hline Food consumption & - & $10.26 \pm 0.84$ & $10.97 \pm 0.73$ & $11.66 \pm 0.61$ & $11.97 \pm 0.97$ \\
\hline Water intake & - & $20.34 \pm 1.46$ & $17.06 \pm 1.01$ & $19.23 \pm 1.04$ & $18.60 \pm 1.29$ \\
\hline Faecal output & - & $8.37 \pm 1.01$ & $8.37 \pm 0.84$ & $8.53 \pm 0.63$ & $9.37 \pm 1.51$ \\
\hline Urine Output & - & $2.26 \pm 0.35$ & $1.95 \pm 0.23$ & $1.86 \pm 0.31$ & $1.62 \pm 0.32$ \\
\hline \multicolumn{6}{|c|}{ Niprineem tea $250 \mathrm{mg} / \mathrm{kg}$} \\
\hline Body weight & $149.83 \pm 7.82$ & $161.50 \pm 7.94$ & $164.33 \pm 9.86$ & $173.33 \pm 11.97$ & $179.83 \pm 12.69$ \\
\hline Food consumption & - & $10.49 \pm 0.91$ & $9.74 \pm 1.10$ & $11.74 \pm 0.62$ & $12.73 \pm 0.33$ \\
\hline Water intake & - & $17.71 \pm 1.19$ & $16.77 \pm 1.25$ & $19.26 \pm 0.92$ & $18.09 \pm 0.92$ \\
\hline Faecal output & - & $7.17 \pm 0.80$ & $7.34 \pm 0.93$ & $7.60 \pm 0.70$ & $7.97 \pm 0.78$ \\
\hline Urine Output & - & $2.09 \pm 0.18$ & $1.72 \pm 0.08$ & $1.73 \pm 0.10$ & $1.40 \pm 0.16$ \\
\hline \multicolumn{6}{|c|}{ Niprineem tea 500 mg/kg } \\
\hline Body weight & $145.50 \pm 8.51$ & $158.16 \pm 11.13$ & $162.33 \pm 11.51$ & $166.17 \pm 13.32$ & $171.67 \pm 13.50$ \\
\hline Food consumption & - & $10.42 \pm 1.33$ & $9.89 \pm 0.91$ & $11.03 \pm 0.87$ & $12.07 \pm 0.89$ \\
\hline Water intake & - & $16.29 \pm 1.65$ & $15.17 \pm 1.25$ & $19.40 \pm 1.89$ & $17.83 \pm 1.00$ \\
\hline Faecal output & - & $7.26 \pm 0.73$ & $6.97 \pm 0.78$ & $7.40 \pm 0.49$ & $8.50 \pm 0.39$ \\
\hline Urine Output & - & $2.09 \pm 0.41$ & $1.83 \pm 0.32$ & $1.83 \pm 0.34$ & $1.60 \pm 0.47$ \\
\hline
\end{tabular}


Table 4: Haematological of rats after 28-day oral treatment with Niprineem tea extract (NTE).

\begin{tabular}{|c|c|c|c|}
\hline Parameter & Control & NTE $250 \mathrm{mg} / \mathrm{kg}$ & NTE $500 \mathrm{mg} / \mathrm{kg}$ \\
\hline$\overline{W B C}\left(\times 10^{9} / L\right)$ & $3.40 \pm 0.78$ & $4.54 \pm 1.26$ & $4.24 \pm 1.02$ \\
\hline LYM (x 109/L) & $1.95 \pm 0.45$ & $2.73 \pm 0.85$ & $2.31 \pm 0.60$ \\
\hline NEUT (x 109/L) & $0.61 \pm 0.16$ & $0.75 \pm 0.16$ & $0.87 \pm 0.19$ \\
\hline $\mathrm{RBC}\left(\times 10^{12} / / \mathrm{L}\right)$ & $7.67 \pm 0.06$ & $8.00 \pm 0.61$ & $9.25 \pm 0.56$ \\
\hline HGB (g/L) & $145.40 \pm 1.96$ & $163.40 \pm 13.31$ & $188.00 \pm 14.82$ \\
\hline HCT (\%) & $39.70 \pm 0.69$ & $44.02 \pm 3.75$ & $49.31 \pm 2.90$ \\
\hline MCV (fL) & $51.78 \pm 1.00$ & $54.92 \pm 1.12$ & $53.30 \pm 0.29$ \\
\hline MCH (Pg) & $18.99 \pm 0.29$ & $20.44 \pm 0.34$ & $20.26 \pm 0.41$ \\
\hline MCHC (g/L) & $366.60 \pm 2.36$ & $371.60 \pm 1.63$ & $379.80 \pm 7.78$ \\
\hline PLT $\left(10^{9} / \mathrm{L}\right)$ & $659.20 \pm 46.71$ & $495.40 \pm 101.51^{\mathrm{c}}$ & $391.40 \pm 83.07^{\mathrm{c}}$ \\
\hline MPV (fL) & $7.73 \pm 0.21$ & $7.92 \pm 0.62$ & $7.44 \pm 0.29$ \\
\hline PDW (fL) & $14.96 \pm 0.04$ & $15.08 \pm 0.08$ & $20.07 \pm 3.10$ \\
\hline
\end{tabular}

(WBC - white blood cells, LYM - lymphocytes, NEUT - neutrophils, RBC - red blood cells, HGB - haemoglobin, HCT haematocrit, MCV - mean corpuscular volume, $\mathrm{MCH}$ - mean corpuscular hemoglobin, $\mathrm{MCHC}$ - mean corpuscular hemoglobin concentration, PLT - platelets, MPV - mean platelet volume, PWD - platelet distribution width). Data represented as Value \pm $\operatorname{SEM}(\mathrm{n}=5) ;{ }^{\mathrm{p}} \mathrm{p}<0.001$ significant vs control.

Table 5: Serum biochemical parameters of rats after 28-day oral treatment with Niprineem tea extract (NTE).

\begin{tabular}{lccc}
\hline Parameter & Control & NTE 250 mg/kg & NTE 500 mg/kg \\
\hline Glucose (mg/dl) & $183.49 \pm 31.67$ & $191.00 \pm 33.07$ & $190.01 \pm 14.08$ \\
Total Protein g/dl & $5.97 \pm 0.12$ & $6.40 \pm 0.23$ & $6.65 \pm 0.34$ \\
Urea (mg/gl) & $50.04 \pm 1.83$ & $45.08 \pm 3.07$ & $48.49 \pm 1.57$ \\
Creatinine (mg/dl) & $2.29 \pm 0.98$ & $2.32 \pm 0.04$ & $2.23 \pm 0.06$ \\
Uric acid (mg/dl) & $3.75 \pm 0.23$ & $4.06 \pm 0.39$ & $4.64 \pm 0.38$ \\
K$^{+}(\mathbf{m m o l} / \mathbf{L})$ & $6.90 \pm 0.30$ & $7.37 \pm 0.92$ & $7.47 \pm 0.69$ \\
Na $^{+}$(mmol/L) & $150.92 \pm 3.91$ & $145.94 \pm 0.85$ & $146.80 \pm 2.55$ \\
Cl$^{-}(\mathbf{m E q} / \mathbf{L})$ & $42.70 \pm 0.61$ & $42.37 \pm 0.41$ & $41.89 \pm 1.40$ \\
HCO$^{-}$(mml/L) & $39.37 \pm 2.84$ & $36.99 \pm 0.68$ & $36.40 \pm 0.86$ \\
Total Cholesterol (mg/dL) & $74.23 \pm 2.05$ & $73.44 \pm 0.86$ & $77.42 \pm 2.46$ \\
Triglycerides (mg/dL) & $93.72 \pm 6.13$ & $97.44 \pm 7.26$ & $98.43 \pm 8.23$ \\
HDL (mg/dL) & $74.04 \pm 3.40$ & $71.01 \pm 2.63$ & $67.22 \pm 1.09$ \\
LDL (mg/dL) & $18.55 \pm 4.36$ & $17.06 \pm 1.90$ & $11.48 \pm 2.34$ \\
ALP (U/L) & $790.46 \pm 92.65$ & $579.05 \pm 85.23^{\mathrm{d}}$ & $502.87 \pm 79.66^{\mathrm{d}}$ \\
ALT (U/L) & $25.79 \pm 2.97$ & $26.35 \pm 3.19$ & $26.99 \pm 2.99$ \\
AST (U/L) & $65.58 \pm 5.91$ & $62.53 \pm 5.11$ & $69.79 \pm 4.46$ \\
Total Bilirubin (mg/dL) & $1.43 \pm 0.05$ & $1.49 \pm 0.08$ & $1.58 \pm 0.10$ \\
Direct Bilirubin (mg/dL) & $1.33 \pm 0.08$ & $1.41 \pm 0.08$ & $1.49 \pm 0.11$ \\
Albumin (g/dL) & $2.84 \pm 0.07$ & $2.98 \pm 0.05$ & $3.21 \pm 0.18$ \\
Globulin (g/dL) & $3.12 \pm 0.11$ & $3.42 \pm 0.27$ & $3.45 \pm 0.36$ \\
\hline
\end{tabular}

$\mathrm{K}^{+}=$potassium, $\mathrm{Na}^{+}$Sodium $=\mathrm{Cl}^{-}=$chloride, $\mathrm{HCO}_{3}^{-}=$Bicarbonate, $\mathrm{HDL}=$ High density lipoprotein, $\mathrm{LDL}=$ Low density lipoproteins, Alkaline phosphatase (ALP), Alanine transaminase (ALT), Aspartate transaminase (AST). Data represented as Value \pm SEM $(n=5) ;{ }^{d} \mathrm{p}<0.0001$ significant vs control Two-way ANOVA. 
Table 6: Relative organ weight of rats after 28-day oral treatment with Niprineem tea extract (NTE).

\begin{tabular}{lccc}
\hline Organ & Control & NTE $250 \mathbf{~ m g} / \mathbf{k g}$ & NTE 500 $\mathbf{~ m g} / \mathbf{k g}$ \\
\hline Heart & $0.35 \pm 0.03$ & $0.31 \pm 0.02$ & $0.32 \pm 0.01$ \\
Liver & $3.79 \pm 0.37$ & $3.51 \pm 0.17$ & $3.52 \pm 0.84$ \\
Lungs & $0.87 \pm 0.18$ & $0.73 \pm 0.06$ & $0.83 \pm 0.11$ \\
Spleen & $0.50 \pm 0.05$ & $0.43 \pm 0.07$ & $0.48 \pm 0.07$ \\
Kidney (L) & $0.33 \pm 0.03$ & $0.31 \pm 0.01$ & $0.32 \pm 0.02$ \\
Kidney (R) & $0.34 \pm 0.04$ & $0.30 \pm 0.02$ & $0.33 \pm 0.02$ \\
Stomach & $1.56 \pm 0.27$ & $1.57 \pm 0.12$ & $1.44 \pm 0.17$ \\
Brain & $0.90 \pm 0.13$ & $0.77 \pm 0.09$ & $0.85 \pm 0.10$ \\
\hline
\end{tabular}

(L - left, R - Right); Data presented as Mean \pm SEM; Two-Way ANOVA, no significant difference treatment vs control group $\mathrm{p}<0.05$.

Table 7: Cellular architecture of rat internal organs after 28-day oral treatment with Niprineem tea extract (NTE).

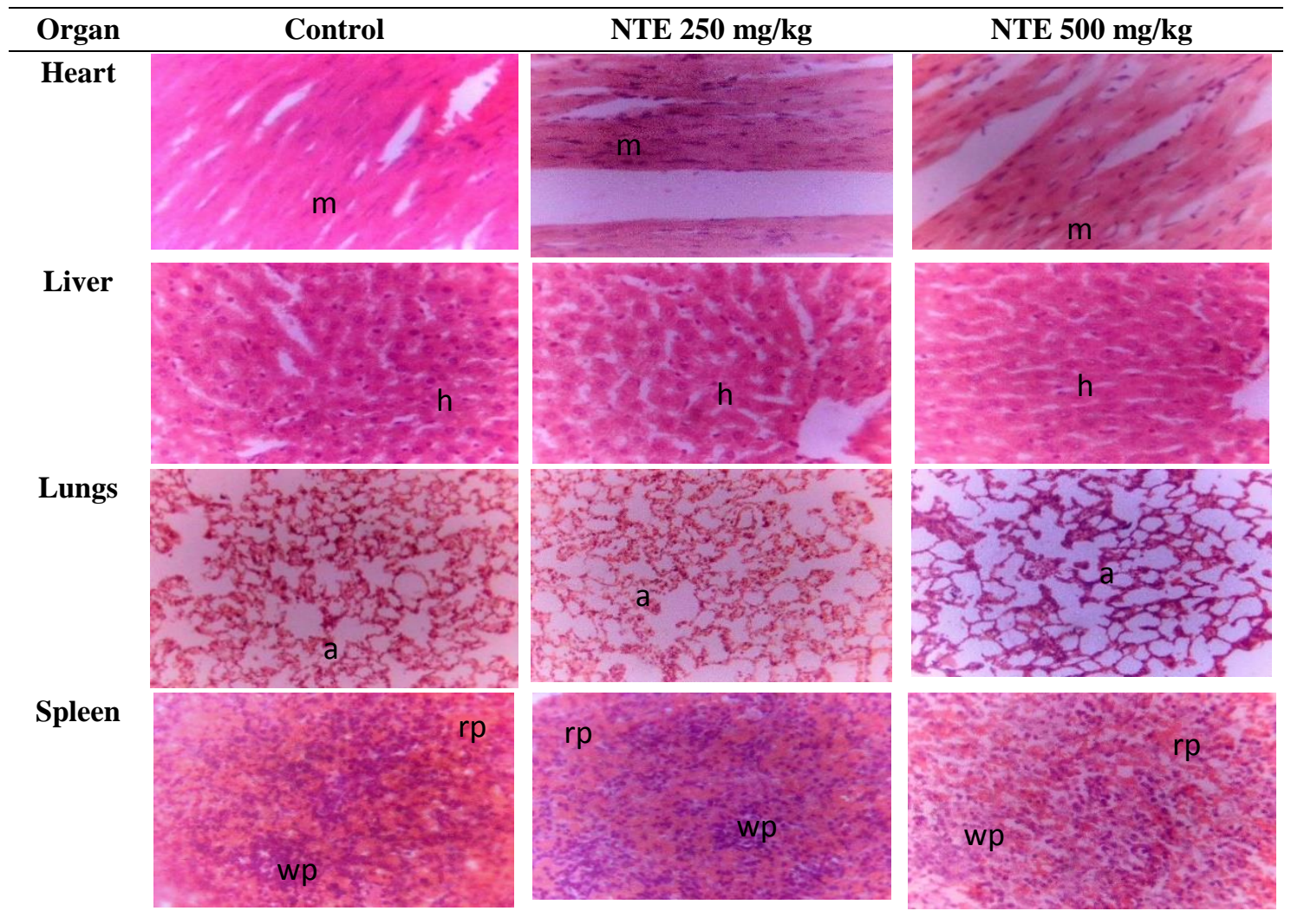




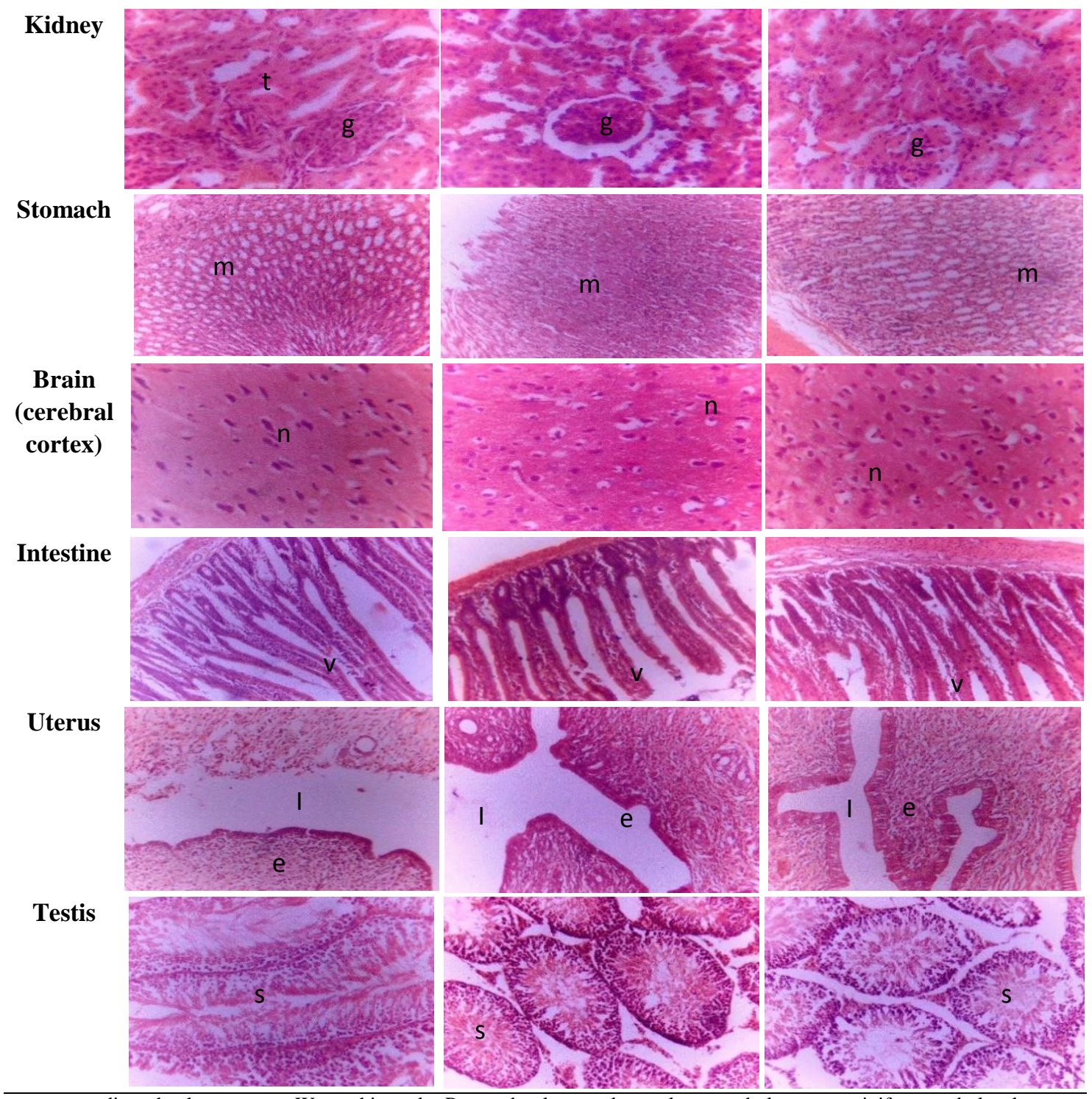

m - myocardium, h - hepatocytes, Wp - white pulp, Rp - red pulp, g - glomerulus, $\mathrm{t}$ - tubules, $\mathrm{s}$ - seminiferous tubules, 1 lumen, e - endometrium, a - alveoli, Ta - tubular adhesion, $\mathrm{n}$ - neuron, $\mathrm{v}$ - villi, $\mathrm{m}$ - stomach mucosa. Histological sections of rat organs (heart, liver, kidney, spleen, lungs, stomach, cerebral cortex, testis, small intestine, uterus) show normal cellular architecture after 28-day oral administration of the aqueous leaf extract (H and E stained x100).

\section{DISCUSSION}

Toxicity evaluations are an essential part of the development of a drug article meant for human use irrespective of the route of application, thus toxicity studies were conducted on Niprineem tea designed for use as a nutritional supplement to prevent or mitigate the effects of diseases. Oral acute and sub-chronic toxicity tests were conducted on Niprineem tea to determine the potential short- term and long-term adverse effects that might occur during the use of the products or due to accidental or deliberate oral exposure to a high dose of these products. The Niprineem tea with $\mathrm{LD}_{50}$ greater than $5000 \mathrm{mg} / \mathrm{kg}$ can be regarded as practically non-toxic (OECD, 2001) suggesting that the product does not possess the potential to produce acute lethal effects on use via the oral route. 
Sub-chronic studies are conducted to determine the possible adverse effect of drugs/test agents after repeated administration for a period of time. Administration of the tea extract did not cause significant changes in the bodyweight of animals. Food and water consumption, faecal and urine excretion were not significantly altered which is an indication that food nutrient absorption and utilization were not affected by Niprineem tea (Balogun and Ashafa, 2016).

Organ weight change is an indicator of chemically induced change in biological systems and is routinely carried out in toxicological studies. The organ of interest varies according to the specifications of the study. For example, in carcinogenicity studies, the presence of tumours may cause variability in organ weights in long-term studies. The kidneys and liver may also be of focus because they are considered to be sensitive in prediction of toxicity due to their involvement in metabolism thus, they reflect physiologic alterations (Michael et al., 2007). In this study, analysis of the relative organ weights of rats treated with Niprineem tea did not show substantial change between treated and control groups suggesting that constituents of Niprineem tea may not cause significant alterations of normal physiologic processes that could present with toxicological manifestations in internal organs.

Toxicity tests can be carried out to determine specific endpoints such as mutagenicity, teratogenicity, skin irritation or propensity to cause specific or generalized organ damage. This information can be deduced from the evaluation of haematological and biochemical parameters. Haematological parameters are indicators used to diagnose the physiological status of an organism (Arika et al., 2016). Haematological analysis of samples collected after 28-days repeated oral administration of treatment with the tea extract did not cause wide range changes in the values of the blood parameters.
Azadirachta indica, the component of Niprineem tea, has been reported as a heamatopoietic agent with the potential of improving anemia (Iyare and Obaji, 2014). This effect on blood parameters could be traced to its flavonoid (quercetin) components that have been shown to influence the levels of haematological parameters (Pasdar et al., 2020). Although there was a trend of increasing values in the parameters of the heamatologic parameters such as RBC, the overall effect was not significantly different between the control and treated groups. A significant decrease in platelets count was however observed even though the mean platelet volume (MPV) and platelet distribution width (PDW) were not significantly different from control groups. Decreased platelet count has been associated with the use of both orthodox and herbal medicines and nutritional supplements (Royer et al., 2010). The platelet number alone does not provide adequate information on the state of platelet maturity and function, therefore, MPV and PDW which are specific and sensitive are useful parameters in the evaluation of platelet disorders (Khairkar et al., 2016). In this study MPV and PDW values of treated animals are comparable to control groups thus the low platelet count may not be a conclusive indication of blood dyscrasias caused by treatment with Niprineem tea extract.

Biochemical analysis for indicators of renal function showed no alteration in electrolytes level. The lipid profile of treated group was similar to control. Diagnostic liver function enzymes aspartate transaminase (AST) and alanine transaminase (ALT) were similar to control, except alkaline phosphatase (ALP) levels which were significantly reduced on treatment with Niprineem tea extract. EzzDin et al. (2011) observed decreased ALP levels in normal rats and rats with induced hepatic injury on treatment with extract of Azadirachta indica which is a component of Niprineem tea. Most hepatic pathologies are 
associated with elevated levels of ALP and other enzymes that include AST and ALT. Decreased in ALP levels in this study may therefore be associated with hepatoprotective function which has been demonstrated for $A$. indica in previous studies (Nwobodo et al., 2018). Bilirubin, albumin, and globulin were not significantly different from control.

Histology examines cell and tissue characteristics in order to detect abnormality in forensic investigation, diagnose an ailment or aid treatment. In this study Niprineem tea extract had no detectable deleterious effects on cellular and tissue structures, indicating that the extract may not contain principles that could alter normal cell function and growth (Alturkistani et al., 2015). Analyses of body fluids of animals have high relevance and predictive value for human toxicology (Rhiouani et al., 2008; Alturkistani et al., 2015).

\section{Conclusion}

The results obtained in this study suggest that the use of Niprineem tea should be within the recommended doses as a high dose may present with toxicity effects. It can then be concluded that Niprineem tea is relatively nontoxic and safe at recommended doses.

\section{COMPETING INTERESTS}

The Authors declare that they have no competing interests.

\section{AUTHORS' CONTRIBUTIONS}

OPA: Conceptualization of the project and revision of the manuscript. BA: study design, critical revision of the manuscript. LBJA: study design, data collection, analysis and interpretation, manuscript development. GA: data collection and drafting of the manuscript. AMD: manuscript development and revision of the manuscript. JAI: revision of the manuscript. All authors approved the final manuscript submitted.

\section{ACKNOWLEDGEMENTS}

The authors wish to acknowledge the technical assistance of Sunday Dzarma and Solomon Ameh Fidelis. This study was funded by National Institute for Pharmaceutical Research and Development, Idu, Abuja.

\section{REFERENCES}

Aladakatti RH, Ghodesawar MAG, Ahmed M, Totiger TM, Sannadurgappa D. 2010. Effect of lyophilized Azadirachta indica leaf powder on biochemical parameters of testis and epididymis in albino rats. Int. $J$. Biol. Chem. Sci., 4(1): 75 - 87. DOI: 10.4314/ijbcs.v4i1.54233

Alturkistani HA, Tashkandi FM, Mohammedsaleh ZM. 2015. Histological stains: A literature review and case study. Glob J. Health Sci., 8(3): 72 - 79. DOI: 10.5539/gjhs.v8n3p72

Alzohairy MA. 2016. Therapeutic role of Azadirachta indica (Neem) and their active constituents in diseases prevention and treatment. Evid-Based complementary Altern. Med., 2016 (Article ID 7382506): 11 p. DOI: https://doi.org/10.1155/2016/7382506

Arika WM, Nyamai DW, Musila MN, Ngugi MP, Njagi ENM. 2016. Hematological Markers of In-vivo Toxicity. J. Hematol. Thromboembolic Dis., 4(2): 100263. DOI: $10.4172 / 2329-8790.1000236$

Ashafa AOT, Orekoya LO, Yakubu MT. 2012. Toxicity profile of ethanolic extract of Azadirachta indica stem bark in male Wistar rats. Asian Pac. J. Trop. Biomed., 2(10): 811-817. DOI: 10.1016/S22211691(12)60234-2

Bakr SA. 2013. Evaluation of acute toxicity of water extract of Azadirachta indica leaves and seeds in rats. Pak. J. Biol. Sci., 16(14): 697-700. DOI: 10.3923/pjbs.2013.697.700

Balogun FO, Ashafa AOT. 2016. Acute and sub-chronic oral toxicity evaluation of aqueous root extract of Dicoma anomala 
Sond. In Wistar rats. Evid-Based Complementary Altern. Medicine, 2016: (Article ID 3509323): 14p. DOI: https//doi.org/10/1155/2016/3509323

Chandrasekara A, Shahidi F. 2018. Herbal beverages: Bioactive compounds and their role in disease risk reduction - A review. J. Tradit. Complement. Med., 8(4): $\quad 451-458 . \quad$ DOI: 10.1016/j.jtcme.2017.08.006

Elteraifi IE, Hassanali A. 2011. Oil and Azadirachtin contents of neem (Azadirachta indica A. Juss) seed kernels collected from trees growing in different habitats in Sudan. Int. J. Biol. Chem. Sci., 5(3): 1063-1072. DOI: 10.4314/ijbcs.v5i3.72211

Ezz-Din D, Gabry MS, Farrag ARH, Abdel Moneim AE. 2011. Physiological and histological impact of Azadirachta indica (neem) leaves extract in a rat model of cisplatin-induced hepato and nephrotoxicity. J. Med. Plants Res., 5(23): 5499 - 5506. DOI: https//doi.org/10.5897/JMPR.9000.980

Fatoba PO, Adeyemi SB, Adewole AA, Fatoba MT. 2018. Medicinal plants used in the treatment of diseases in South Western Nigeria. Nig. J. Basic and Applied Sci., 26(1): 14-22. DOI: http://dx.doi.org/10.4314/njbas.v26i1.2

Hossain MA, Al-Toubi WAS, Weli AM, AlRiyami QA, Sabahi JN. 2013. Identification and characterization of chemical compounds in different crude extracts from leaves of Omami neem. J. Taibah Univ. Sci., 7(4): 181-188. DOI: https://doi.org/10/1016/j.jtusci.2013.05.0 03

Islas JF, Acosta E, G-Buentello Z, DelgadoGallegos JL, Moreno-Trevino MG, Escalante B, Moreno-Cuevas JE. 2020. An over view of Neem (Azadirachta indica) and its potential impact on health. J. Funct. Foods, 74: 104171. DOI: https://doi.org/10.1016/j.jff.2020.104171
Iyare EE, Obaji NN. 2014. Effect of aqueous leaf extract of Azadirachta indica on some haematological parameters and blood glucose level in female rats. Niger J. Exp. Clin. Biosci., 2(1): 54-58. DOI:10.4103/2348-0149.135731

Jeba Malar TRJ, Antonyswamy J, Vijayaraghavan P, Kim YO, Al-Ghamdi AA, Elshikh MS, Hatamlel AA, AlDosary MA, Na SW. 2020. In-vitro phytochemical and pharmacological bioefficacy studies on Azadirachta indica A. Juss and Melia azedarach Linn for anticancer activity. Saudi J. Biol. Sci., 27(2): $682-688 . \quad$ DOI: https://doi.org/10.1016/j.sjbs.2019.11.02 4

Khairkar PS, Pandey A, More S, Pande M. 2016. Platelet distribution width (PDW) A rarely studied platelet indicator for determining the cause of thrombocytopenia. Ann. Int. Med. Dental. Res., 2(4): 193 - 197. DOI: 10.21276/aimdr.2016.2.4.49

Mahabub-Uz-Zaman M, Ahmed NU, Akter R, Ahmed K, Aziz MSI, Ahmed MS. 2009. Studies on anti-inflammatory, antinociceptive and antipyretic activities of ethanol extract of Azadirachta indica leaves. Bangladesh J. Sci. Ind. Res., 44(2): 199 -206.

Mahmoud DA, Hassanein NM, Youssef KA, Abou Zeid MA. 2011. Antifungal activity of different neem leaf extracts and the nimonol against some important human pathogens. Braz. J. Microbiol., 42(3): 1007 - 1016. DOI: $10.1590 /$ S1517838220110003000021

Malone MH, Robichaud RC. 1962. A Hippocratic screen for pure or crude drug materials. Lloydia, 25(4): 320 - 332. http://www.fefar.unesp.br/arquivos/4835 24.pdf. 1

Michael B, Yano B, Sellers R, Perry R, Morton D, Roome N, Johnson JK, Schaffer K, Pitsch S. 2007. Evaluation of organ 
weights for rodent and non-rodent toxicity studies: A review of regulatory guidelines and a survey of current practices. Toxicol. Pathol., 35(5): $742-$ 750. DOI: $10.1080 / 01926230701595292$

Mondédji AD, kasseney BD, Nyamador WS, Abbey GA, Amévoin K, Ketoh GA, Adoléglitho I. 2016. Effects of neem (Azadirachta indica A. Juss) leaves hydroethanolic extract on Plutella xylostella (Lepidoptera: Plutellidae) and Lipaphis erysimi (Hemiptera: Aphididae) in cabbage production in Southern Togo. Int. J. Biol. Chem. Sci., 10(4): 1666 1677. DOI: $10.4314 /$ ijbcs.v10i4.18

Nwachukwu N, Iweala EJ. 2009. Influence of extraction methods on the hepatotoxicity of Azadirachta indica bark extract on albino rats. Global J. Pure Appl. Sci., 15: 369-372. DOI: 10.4314/gjpas.v15i34.48562

Nwobodo EI, Nwosu DC, Ogbodo SO, Ugwuene FO, Ihim AC, Ani NO, Nnodim JK, Ani O. 2018. Effects of Azadirachta indica leaf aqueous extract on the antioxidant enzymes in paracetamolinduced hepatotoxicity in Wistar rats. Int. J. Biol. Chem. Sci., 12(1): 1 - 10. DOI: 10.4314/ijbcs.v12i1.1

OECD guideline for the testing of chemicals. 2001. Acute Oral Toxicity - Acute Toxic Class Method No 423. OECD, France. DOI: $10.1787 / 9789264071001-e n$

OECD guideline for the testing of chemicals. 2008. Repeated dose 28-day oral toxicity in rodents, study procedure No 407. OECD, France. DOI. https://doi.org/10.1787/20745788

Ogbuewu IP, Odoemenam VU, Obikaonu HO, Opara MN, Emenalom OO, Uchegbu MC, Okoli IC, Esonu BO, Iloeje MU. 2011. The growing importance of Neem (Azadirachta indica. Juss) in agriculture, industry, medicine and environment: A review. Res. J. Med. Plant, 5(3): $230-$ 245. DOI: $10.3923 /$ rjmp.2011.230.245

Pasdar Y, Oubari F, Zarif MN, Abbasi M, Pourmahmoudi A, Hosseinikia M. 2020. Effects of quercetin supplementation on hematological parameters in nonalcoholic fatty liver disease: a randomized, double-blind, placebocontrolled pilot study. Clin. Nutr. Res., 9(1): $11-19 . \quad$ DOI: https://doi.org/10.7762/cnr.2020.9.1.11

Reagan-Shaw S, Nikal M, Ahmad N. 2007. Dose translation from animal to human studies revisited. FASEB J., 22: 659 661. DOI: 10.1096/fj.07-9574LSF

Rhiouani H, El-Hilaly J, Israili ZH, Lyoussi B. 2008. Acute and subchronic toxicity of an aqueous extract of the leaves of Herniaria glabra in rodents. J. Ethnopharmacol., 118(3): $\quad 378-386 . \quad$ DOI: 10.1016/j.jep.2008.05.009

Royer D, George JN, Terrell DR. 2010. Thrombocytopenia as an adverse effect of complementary and alternative medicines, herbal remedies, nutritional supplements, foods and beverages. Eur. J. Haematol., 84(5): 421-429. DOI: 10/111/j.1600-0609.2010.01415.x

Sadeghian MM, Mortazaienezhad F. 2007. Investigation of compounds from Azadirachta indica (Neem). Asian $J$. Plant Sci., 6: 444 - 445.

Talib WH, AL-Ataby IA, Mahmod AS, Jawarneh S, Al Kury LT, AL-Yasari IH. 2020. The Impact of herbal infusion consumption on oxidative stress and cancer: The Good, the bad, the misunderstood. Molecules, 25(18): 4207. DOI: 10.3390/molecules25184207

Tiwari R, Verma AK, Chakraborty S, Dhama K, Singh SV. 2014. Neem (Azadirachta indica) and its potential for safeguarding health of animals and humans: A review. J. Biol. Sci., 14(2): 110 - 123. DOI: 10.3923/jbs.2014.110.123 